\title{
Preschool Children's Learning Opportunities Using Natural Numbers in Number Row Activities
}

\author{
Maria Alkhede ${ }^{1,2} \cdot$ Mona Holmqvist $^{3}$ (])
}

Accepted: 24 September 2020 / Published online: 4 November 2020

(c) The Author(s) 2020

\begin{abstract}
This study analysed how preschool teachers differently enacted the same mathematical activity for preschool children to discern numbers, and how this affected the children's learning opportunities during the activity. The analysis was based on variation theory and Chi's taxonomy of learning activities. Two Swedish preschool teachers' enactment of the same mathematical activity for 27 children aged 4-6 years was studied. Video recordings of what the children were offered to discern were used in the analysis. The results indicate that variations in how the teachers chose to enact the activity produced two different learning opportunities for the children. Differences in what aspects were made discernible were closely linked to the characteristics of the activity implemented. The enactments differed even if the same game was chosen and the same amount of time was used in the play-based activity. In one preschool group, there were few opportunities to discern more than the nominal form of numbers; the other preschool group had an activity focused on all number forms simultaneously. In addition, in the latter group, the children had the opportunity to develop equinumerosity. The results suggest that the activity with limited variation was more appropriate for learning with undeveloped knowledge; the children with more developed understanding required a more varied design. This study contributes to the knowledge of how the design of an activity affects children's learning differently, which is important when planning learning-based preschool activities.
\end{abstract}

Keywords Preschool mathematics $\cdot$ Number forms $\cdot$ Cardinality $\cdot$ Equinumerosity

\section{Introduction}

Designing mathematical learning activities for children in preschool is important and sometimes challenging for teachers. Pyle and Bigelow (2015) found that kindergarten teachers implemented play to develop children's learning in their daily work differently, depending on personal beliefs of their own role in the activity. Play is an activity with many forms. Taylor and Boyer (2020) identified different types of playbased learning (PBL) in kindergarten. They distinguished between teacher- and child-directed play. Regardless of the teacher's direction, an activity is designed to offer learning

Mona Holmqvist

mona.holmqvist@mau.se

1 Department of Children, Youth and Society, Malmö University, Malmö, Sweden

2 Department of Education, Communication and Learning, University of Gothenburg, Gothenburg, Sweden

3 Department of School Development and Leadership, Malmö University, Malmö, Sweden opportunities for the children and to affect their learning. Children's active participation in the learning situation was found to be the most important factor for designing effective teaching interventions to develop children's mathematical ability (Papadakis et al. 2017).

In research on how to improve preschool mathematics education in play-based kindergarten activities, four different forms of mathematics pedagogy used by teachers were identified: free play, guided play, teacher-directed play, and direct instruction (Wickstrom et al. 2019). The results also showed that play was the main arena of observed mathematical activities; teacher-directed play was the main arena for 'math incidents' (p. 294) supporting the children's active participation. The study presented in that article was in a Swedish preschool context. Björklund and Barendregt (2016) have defined such a context as a learning environment that is supposed to work with mathematics, as it occurs in children's self-initiated activities; however, the learning environment also has to make it possible to explore a specific mathematical principle in goal-oriented play and meaningful activities (p. 371). By analysing a questionnaire answered 
by 116 teachers, Björklund and Barendregt found that goaloriented activities were rarer than the children' self-initiated activities. Breive et al. (2018) found in their design-based study that kindergarten teachers following the instructions of activities for mathematical learning "'lost opportunities" for adopting an inquiry approach to the learning of mathematics and that playful learning was implemented to a limited degree' (p. 196). Lerkkanen et al. (2016) argue that child-centred and teacher-directed activities in preschool are based on different theoretical assumptions. The child-centred approach is founded on constructivist theory: children are seen as constructors of knowledge, and the teachers' role is more of a facilitator for their learning. By contrast, the teacher-directed approach is based on traditional learning theory and didactics: the teachers are regarded as significant people in contributing with knowledge and challenging children's previous knowledge. Those authors' results indicate a strong positive effect of child-centred activities for children's learning.

The focus of learning in the present study is understanding the different forms of natural numbers. One argument for this choice is that cardinality (i.e., giving a number word that represents an entire set of entities) has been found to be important for children's mathematical learning (Resnick 1983; Cross et al. 2009)—both in a short- and long-term perspective. Children who enter school with developed mathematical understanding are more likely to succeed in future mathematical learning (Papadakis et al. 2017). Further, a developed understanding of the distinction between cardinal and ordinal forms of numbers is required to understand equinumerosity. Equinumerosity (Sarnecka and Wright 2013) refers to the knowledge that a number (e.g., two) corresponds only to exactly that number of items (e.g., two spoons, not three spoons). If children develop equinumerosity, they also understand cardinality (Sarnecka and Wright 2013). Cardinality is the knowledge of the succession in a number row by adding one item to the previous item. If the child is not aware of the addition of one item, they might understand numbers as labels (nominal understanding) or as words in a number chant (ordinal understanding). The sequence of counting words is one of the most important tools of early mathematics learning (Fuson 1992). Young children's initial contact with numbers probably occurs when they first use the words for numbers in a song, a poem, or perhaps when they count some objects in a context. Thus, young children are introduced to number symbols early in their learning environment (Fuson 1992; Clements and Sarama 2007) by learning numbers as labels or names without knowing what amounts they represent: 'In these cases the fact that a child says the correct number word does not ensure that the child has understood or is using the cardinal, ordinal, or measure numerical reference of the symbol' (Fuson 1988, pp. 12-13). To enhance the children's understanding of numbers, discernment of diversity in number representations (i.e., written symbols, spoken symbols, real-world situations, and manipulative models and pictures) affect the children's learning opportunities (Lesh 1981). Simultaneously, discernment of numbers in different shapes, both in the form of representation as well as cardinal and ordinal, is important for children's future mathematical performance (Fuson 1988; McIntosh et al. 1992). The understanding of cardinality is the key to success for developing a number sense; thus, an important field of study is to obtain more knowledge about how teaching can be designed to offer children their best learning opportunities.

This study analysed how preschool teachers differently enacted the same mathematical activity for preschool children to discern numbers and how this affected the children's learning opportunities during the activity. The study addresses the following questions:

RQ1. What differences are evident in two preschool teachers' enactment of the same mathematical activity for children?

RQ2. How do those differences contribute to the variety of learning opportunities for the children?

\section{Number Sense}

Number sense refers to a person's general understanding of numbers and operations along with the ability and inclination to use this knowledge in flexible ways. Number sense is crucial for making mathematical judgements and developing useful strategies for handling numbers and operations (McIntosh et al. 1992). This concept has been well researched in the literature over many years. Research attempts to describe number sense include the meaning of numbers (Brownell 1947), multiple representations (McIntosh et al. 1992), understanding of quantity (Davydov 1982; Wynn 1989), partial-whole knowledge (Carpenter and Moser 1982), various uses of number words (Fuson and Hall 1983), knowledge about magnitude (McIntosh et al. 1992; Howden 1989; Baroody 1987), computing and counting strategies (Reys and Reys 1995), a benchmark system (McIntosh et al. 1992), and using numbers in operations (McIntosh et al. 1992; Cross et al. 2009; Gelman and Gallistel 1986; Davydov 1982).

Four mathematical aspects for understanding and managing number sense in early childhood have been identified (Cross et al. 2009): cardinality (i.e., giving a number word for a set of entities); number word list (ordinal; i.e., knowing the number sequence); one-to-one counting correspondence (equinumerosity), where numerals correspond to objects; and written numerical symbols. Reading, writing, and understanding written number symbols are also 
important in reference to the nominal form of numbers. These four aspects are initially separated in teaching children to gradually learn to detect and use them in different situations in an integrated and simultaneous way. When using numbers, adults do not need to distinguish between the number's ordinal and cardinal meanings. However, children first learn these meanings individually and then must link them together (Cross et al. 2009). To perform a calculation, it is necessary to have knowledge of several aspects simultaneously. Using numbers in numerical operations or arithmetic problem-solving requires the knowledge of numbers' cardinality and ordinality (i.e., a number word may determine the quantity of a set and number words are related to each other in orderly fashion) (Gelman and Gallistel 1986).

The research results stress the importance of fully understanding cardinality (Resnick 1983; Cross et al. 2009). Among Gelman and Gallistel's (1986) five principles for enumeration, the cardinal principle is found to be the most challenging, but also the key to successfully developing number sense. To correctly determine a number, it is necessary to use two more of these principles (i.e., one-to-one correspondence, equinumerosity) and stable order, simultaneously. Children, aged between three and five, are beginning to develop their cardinal understanding of numbers. Understanding cardinality requires the understanding that it is not dependent on enumeration, but relates to a multitude (Wynn 1992). Very young children also have knowledge about cardinality, which starts with subitising (i.e., perceiving a small amount [three to four] without counting) (Clements 1999). The concept of subitising was defined by Kaufman et al. (1949): 'We wish to avoid terms now in use, having other meanings, and terms with the misleading connotations of estimating, counting, or grasping by intuition. The term proposed is subitize' (p. 520). There are two types of subitising: perceptual and conceptual. Children use perceptual subitising as a prelude to understanding cardinality (Clements 1999). Conceptual subitising is about using a pattern to perceive a (larger) number, e.g., two pictures with four dots on each, resulting in eight dots. Here, conceptual subitising can be linked to arithmetic abilities, such as calculations and operating with numbers. Research results show that understanding cardinality is the basis for counting, operating with numbers, and other complex skills involving addition and subtraction (Fuson 1992; Wynn 1992; Clements and Sarama 2014). In their study, Bermejo et al. (2004) showed that children's cardinality learning was enhanced if cognitive conflicts were used. The role of the teachers in pointing out contradictions during the interventions was also an important variable.

Besides the discernment of ordinal and cardinal aspects, understanding numbers requires the discernment of the diversity of numbers and the variation in representations of the same number. Understanding and using numbers as mathematical concepts in different situations requires a translation process to map between these contexts, as explained in a model by Lesh (1981). In this model, several aspects of how numbers are translated between contexts and forms of representations are related by the activities into which the representations are translated. For example, manipulative models can be used to symbolise written symbols, but written symbols can also be concretised using manipulative models. Manipulative models can also be used to describe particular details of real-world situations as well as generalisations for them (Fig. 1).

Number sense itself contains several components; therefore, learning and development in this field becomes an intricate and complex process. By giving children the opportunity to discover and discern all these number forms simultaneously, their number sense can be developed (i.e., the children can develop their ability to perceive, pronounce, describe, discuss, and construct numbers): 'Understanding numbers and related concepts includes understanding concepts of quantity and relative quantity, facility with counting, and the ability to carry out simple operations' (Cross et al. 2009, p. 22). Number sense is about discerning different aspects of numbers and understanding their meaning and importance, in addition to being able to see the meaning of and relevance in using numbers. However, it is well known that the development of an understanding of numbers involves a long process (Fuson 1991; Cross et al. 2009; Gelman and Meck 1992).

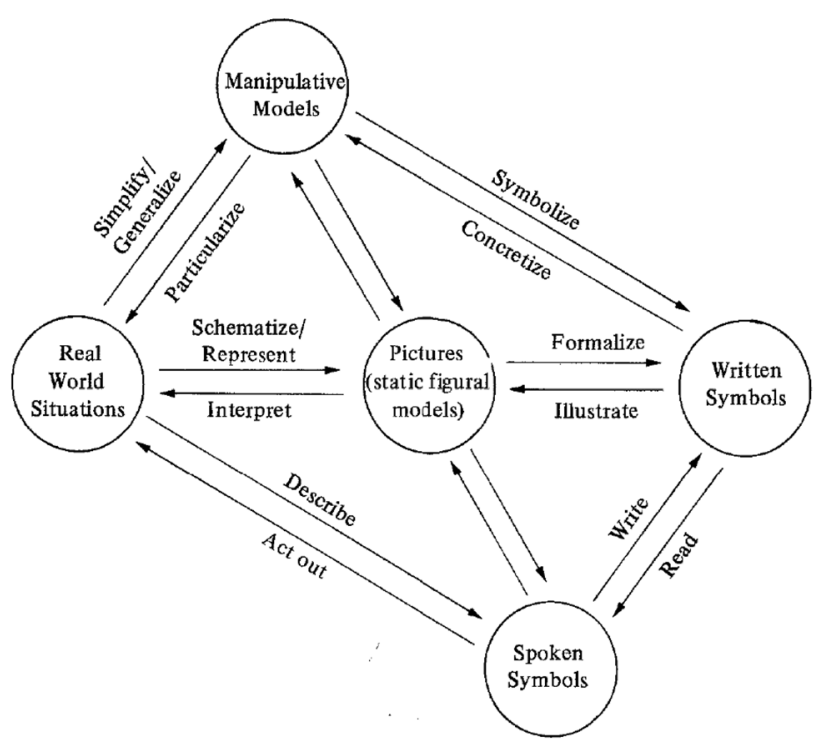

Fig. 1 Lesh's (1981, p. 246) translation processes (with the author's permission) 


\section{Theoretical Frameworks}

\section{Chi's Taxonomy of Activities}

The long process of learning numbers consists of different kinds of learning opportunities in activities with diverse supports. Wickstrom et al. (2019) found that children's mathematical play-based learning in preschool has four different forms: free play, guided play, teacher-directed play, and direct instruction. However, this is a definition of the characteristics of the forms of the activities: Wickstrom et al. (2019) do not define how the children's active participation is related to the content.

The taxonomy of Chi (2009) allows activities to be defined as active, constructive, or interactive (Table 1). This means that free play, guided play, teacher-directed play, and direct instruction can be defined as active, constructive, or interactive. Being active is characterised by physically doing something, such as pointing, talking, looking, and showing, in response to materials or forms of communication; it constitutes overt activity. Cognitive processes are suggested as activating previous knowledge as well as attending to and storing new information. At the next level (constructive activities), the child produces outputs that go beyond the information they have received. Overt activities are explanations, connecting previous knowledge to new knowledge: the child reflects and plans in new ways. Cognitive processes when a child constructs new knowledge are, for example, when they create new knowledge by merging previous knowledge with new knowledge, correct inaccuracies, and organise their own knowledge. Finally, interactive activities are characterised by a dialogue about the same topic with respect to other people's perspectives and comments. Overt activities are, for example, when a child confronts or defends their knowledge, revises their arguments or actions based on feedback from others, or responds to support. Cognitive processes involve taking other people's contributions into consideration. This means that whatever the form of learning activity, children's active participation can more or less develop according to how involved they are in the learning processes: 'The framework consists of a taxonomy that generates a hypothesis, that interactive activities might be better than constructive activities, which in turn might be better than active activities, which would be better than passive activities' (Chi 2009, p. 97).

\section{Variation Theory}

A theoretical framework with assumptions of necessary conditions for learning can guide efforts to determine how a learner understands a defined content (Holmqvist et al. 2014; Marton 2015). To capture a part of the learning process (i.e., the children's expressed understanding), variation theory can be used as an analysis approach to study learning opportunities that have been offered. Variation theory focuses on aspects of the phenomenon that are discernible or not discernible during a learning activity; it captures what was possible for the children to discern during their learning activity (Holmqvist 2011). When based on variation theory, learning requires variation of aspects of the object of learning: that

Table 1 Chi's (2009, p. 77) categorization of overt activities as active, constructive, and interactive

\begin{tabular}{|c|c|c|c|}
\hline & Active & Constructive & Interactive \\
\hline Characteristics & Doing something physically & $\begin{array}{l}\text { Producing outputs that contain ideas } \\
\text { that go beyond the presented infor- } \\
\text { mation }\end{array}$ & $\begin{array}{l}\text { Dialoguing substantively on the same } \\
\text { topic, and not ignoring a partner's } \\
\text { contributions }\end{array}$ \\
\hline Overt activities & $\begin{array}{l}\text { Engaging Activities } \\
\text { Look, gaze, or fixate } \\
\text { Underline or highlight } \\
\text { Gesture or point } \\
\text { Paraphrase } \\
\text { Manipulate objects or tapes } \\
\text { Select } \\
\text { Repeat }\end{array}$ & $\begin{array}{l}\text { Self-construction Activities } \\
\text { Explain or elaborate } \\
\text { Justify or provide reasons } \\
\text { Connect or link } \\
\text { Construct a concept map } \\
\text { Reflect or self-monitor } \\
\text { Plan and predict outcomes } \\
\text { Generate hypotheses }\end{array}$ & $\begin{array}{l}\text { Guided-construction } \\
\text { Activities in Instructional Dialogue: } \\
\text { Respond to scafffoldings } \\
\text { Revise errors from feedback } \\
\text { Sequential or Co-construction } \\
\text { Activities in Joint Dialogue } \\
\text { Build on partner's contribution } \\
\text { Argue, defend } \\
\text { Confront or challenge }\end{array}$ \\
\hline Cognitive processes & $\begin{array}{l}\text { Attending Processes } \\
\text { Activate existing knowledge } \\
\text { Assimilate, encode, or store new } \\
\text { information } \\
\text { Search existing knowledge }\end{array}$ & $\begin{array}{l}\text { Creating Processes } \\
\text { Infer new knowledge } \\
\text { Integrate new information with exist- } \\
\text { ing knowledge } \\
\text { Organize own knowledge for coher- } \\
\text { ence } \\
\text { Repair own faulty knowledge } \\
\text { Repair own faulty knowledge }\end{array}$ & $\begin{array}{l}\text { Jointly Creating Processes } \\
\text { Creating processes that incorporate a } \\
\text { partner's contributions }\end{array}$ \\
\hline
\end{tabular}


variation simultaneously focuses on different aspects that are essential for the content; to develop new knowledge, the simultaneous variation offers the learner the chance to discern what has so far not been discerned. This means that in order to understand the number three, children have to discern what numbers are by discerning the aspect 'numbers' simultaneously with the features one, two, three, and so on, to discern the similarities (numbers) and differences (values) among them. If a child encounters only one number, such as the child's age in years, the child's counting may be the experience of a kind of attribute rather than a number. The way in which the aspects of a phenomenon vary follows a pattern (Holmqvist et al. 2014, which can include contrast, such as contrasting the number three with the number four to ensure that the children experience the difference between them and can separate them. Another pattern of variation is generalisation, which in this case means the possibility for the children to discern different representations of the same thing by separating the principle from its representation. Three is always three no matter whether you use three apples, three flowers, or three teddy bears as examples. Finally, fusion is the highest order of the pattern of variation, which means that several aspects can vary simultaneously. If a child is introduced to the number three, the child will discern the name, its placement in an order (between two and four), and also the amount it represents (three items). Therefore, the child can identify these aspects for each number from among various numbers.

\section{Methodology}

\section{The Context of the Study: A Swedish Preschool}

The Swedish National Agency for Education (2019) states that preschool education, which since 2011 has been included in Sweden's education system, should rest on both a scientific basis and proven experience. The agency emphasises that knowledge is expressed in various forms as facts, understanding, skills, and familiarity, which interact with and presuppose one another. In particular, the agency emphasises the importance of mathematics learning and notes that it helps people to make well-informed decisions in daily life and increases the opportunities to participate in society's decision-making processes (Swedish National Agency for Education (2019). Professionals working in Swedish preschools are mainly preschool teachers, but there are also child minders with no teaching degree. The justification for teaching preschool mathematics is that preschool education should give children the opportunity to use mathematics to investigate and describe their surroundings and solve everyday problems (Swedish National Agency for Education 2016). Preschools should give each child the prerequisites for developing the ability to use mathematics and understand its basic properties, including order and numbers. The preschool mathematics curriculum focuses on two basic elements: room perception (room, time, and form) and number sense (quantities, number, order, and measurement) (Swedish National Agency for Education 2016, 2018).

Children's learning about numbers and counting in the present study, which is part of a larger research project including interventions (Kullberg and Björklund 2019), focuses on four preschools in a small municipality in south-western Sweden during a school year (September-April). Questions such as when and how preschool children learn to count were processed. The study focused on looking at what happens in different activities with mathematics content offered to children at the participating preschools. Four preschool teachers were asked to plan and facilitate an activity with the content of numbers and counting. Two of the activities were chosen because the teachers occasionally based their activities on the same PBL activity. This made it possible to study two different enactments of an activity with the same intentions and learning goals. The specific objectives were to describe the number and nature of the numerical words used in the two activities, and to uncover in what way the differences affected the children's learning opportunities, depending on the combination of different designs and the students' prior knowledge.

In this study, two activities that were found to originate from similar instructions became especially interesting to analyse because the same activity was enacted differently (i.e., the Boxes and Cups activities), which can be defined as a PBL situation (Taylor and Boyer 2020). The activity was inspired by an article in a Swedish journal for mathematics education for teachers and researchers, Nämnaren (https://ncm.gu.se/namnaren), published by the National Center for Mathematics Education in Sweden. In that article, the activity is called 'Where is the treasure?' The activity is aimed at developing knowledge about number sequences and the relationships between numbers. The materials used are 11 cups, labelled with the numbers $0-10$, and something to hide under the cups, e.g., a pearl. One person hides the treasure while the others close their eyes, and then these students propose the cup number under which they think the treasure is hidden. If the chosen cup does not contain the treasure, it is removed. The student who hid the pearl provides a clue regarding 'higher' or 'lower' cup numbers (Olsson and Forsbäck 1998, p. 17), and the search continues. Even though the use of the words 'higher' and 'lower' is problematic because it connotes location rather than quantity, the teachers made this choice following what they read in the Nämnaren article. We preferred the use of the wording 'smaller' or 'bigger' 
number. These two activities were analysed with a focus on the enactment of the learning situation based on two theoretical frameworks, Chi's taxonomy, and variation theory.

\section{Participants}

Two groups of children aged 4-6 years $(n=27)$ and their teachers $(n=5)$ from Swedish preschools participated in this study. The two groups were from preschools B and C-two different preschools in a small municipality in south-western Sweden. The Boxes activity was planned and led by a child minder with 13 years of preschool experience; the Cups activity was planned and led by a preschool teacher with over 10 years of preschool experience. One or two additional teachers were also physically present during the activity, but they did not contribute (Table 2). The participants spoke in Swedish. Written consent was sent to the children's parents and the teachers, collected by the teachers, and then returned to the principal investigator (Camilla Björklund) of the main project, FASETT, financed by the Swedish Research Council (grant number 721-2014-1791). An ethical application for the project was approved by the regional review board (2015-04-27 Dnr: 258-15).

\section{Data-Collection Method}

The data was collected between August 2015 and May 2016. The first author made video recordings using a hand-held camera to capture the activities. These recordings focused on the activity, the teachers, and the children who participated in the activity. The children and their teachers were originally from four preschools. The groups engaged in activities familiar to them in their ordinary preschool environment. There were no interventional aspects to this study; instead, the first author instructed the teachers to plan and enact an activity focusing on numbers and counting to enhance their students' learning in line with their ordinary preschool activities. The choice of the same game for two groups of children at different preschools was a coincidence.
The video recordings from the four preschool groups were long ( $5 \mathrm{~h} 35 \mathrm{~min}$ ), and so the observations made during the project were extensive. Of this entire material, the two focused activities chosen for detailed analysis lasted $26 \mathrm{~min}$ $50 \mathrm{~s}$ for the two groups (12 $\mathrm{min} 20 \mathrm{~s}$ for one; $14 \mathrm{~min} 30 \mathrm{~s}$ for the other); as with the rest of the material, the content was transcribed verbatim. The video recordings of the two preschool groups lasted $58 \mathrm{~min}$ for one and $1 \mathrm{~h} 56 \mathrm{~min}$ for the other. The focused analysis of parts of the video observations began and finished with the targeted activity. Qi et al. (2006) have studied children's behaviour characteristics in teacher-directed structured activities and child-directed unstructured activities; they found an observation time of $60 \mathrm{~min}$ to be sufficient (divided into 10-min periods).

\section{Enactment of the Teachers' Activities and Data Collected}

The teachers' two activities are described briefly here to set the scene of the analysis made to answer this study's aim and research questions. It is important to remember that this is the same activity (based on the treasure activity); however, it was interpreted and enacted differently by the participating teachers. To distinguish between them in this paper, we have named the activities based on the materials used by the teachers (one using cups and the other using boxes to hide the treasure). The Cups activity consisted of a representation of a number row consisting of 10 cups with the numbers 1-10 written on the bottom of the cups, which were placed upside down on a table. No cup represented 0 . The children were sitting in a circle, which meant that for some of the children, the numbers were upside down and the number row (a paper strip) reversed. The teacher placed the cups in a certain order that contradicted with how the number row was placed. A child saw this contradiction and tried to correct the number row into the proper order but was stopped by the teacher. Instead, the teacher changed the order of the cups. The children were asked about the names of the numbers written on the cups, which were placed into the correct order. After this exercise, a small piece of paper (i.e., the treasure) was placed under one of the cups, while
Table 2 Participants, data and number representations

\begin{tabular}{lll}
\hline Mathematical activity & Boxes & Cups \\
\hline Participants (children/teachers) & $14(12 / 2)$ & $18(15 / 3)$ \\
Data collected & Video recording & Video recording \\
& 12 min $20 \mathrm{~s}$ & 14 min 30 s \\
Number representations offered & Digits (written symbols) & Digits (written symbols) \\
& Fingers (real-world situation) & Verbalised (spoken symbols) \\
& Boxes (manipulate models) & \\
& Dots (pictures) & \\
Number of relationships offered & Verbalised (spoken symbols) & \\
\hline
\end{tabular}


one of the children closed her or his eyes. The child was allowed to open his or her eyes and guess where the piece of paper could be found. The other children gave cues such as whether it was higher or lower. The cups that were taken were returned, which made it a bit more difficult as the children forgot what had already been guessed. There was no representation of the cardinality of the numbers, e.g., two combined with the representation of two dots.

In the Boxes activity, the boxes were placed in the same order as the cups in the activity above; however, the numbers on the boxes were supplemented with dots to represent the amount of the number (e.g., three and $\bullet \bullet \bullet)$, and all numbers between 0 and 10 were used. Another difference was that the teacher did not show the boxes in order; the children had to correct the number row by discussing the number order instead. The teacher did not use a separate number row in this activity. A small plastic bear was used as the treasure in this activity. Another difference was that all children had to close their eyes except for the one who was hiding the bear. All of the children became active in trying to find out where the treasure was. The teacher turned the boxes upside down after the number had been taken, and the children received cues such as 'higher' or 'lower' when their guess was incorrect. At the end of the activity, the teacher collected the boxes by asking the children to give her the box representing her three fingers, the box that was higher than eight, and so on. Lesh's (1981) framework showing diversity in number representations (mapped in Fig. 1) was used to visualise the forms of number representations used by the teachers.

\section{Analysis}

The video recordings from two different preschool groups of children aged 4-6 years old were analysed based on two frameworks: variation theory (Marton 2015) and Chi's taxonomy of activities (Chi 2009). The material was transcribed and analysed initially to capture the overall understanding of the two different activities. Both researchers watched the recordings to compare them against the transcriptions for consistency. Parts of the material were also analysed in seminars with other researchers to validate our interpretation. A descriptive analysis was performed initially. The initial descriptive analysis shows the measured number words uttered by the teachers and children. The number words were divided into nominal, ordinal, or cardinal numbers. The discernment of equinumerosity was also analysed. For example, if the child said the cup was number three, it was categorised as nominal; if they said the numbers in order in a number sequence ('one, two, and three'), it was categorised as ordinal; and 'there are three dots' was categorised as cardinal. The equinumerosity category refers to the number that involves both ordinal and cardinal meaning, e.g., when the child counted one, two, and three and recognised that this meant three items: a one-to-one correspondence.

This step was followed by an analysis to capture what aspects were made discernible based on variation theory (Marton 2015). During this part of the analysis, the focus was on what aspects were made discernible for the children separately and simultaneously. One process used to capture what aspects were offered to the children to discern, was to describe the frequency of words used by teachers and children. First, the total amount of number words was determined; they were then divided according to meaning as nominal, ordinal, cardinal, or equinumerosity. The assumption was that activities using different word meanings were also indicators of differences in offered learning possibilities; that was based on an assumption of variation theory about what becomes discernible. The second step of the variation theory analysis examined what simultaneous opportunities the activities offered concerning number forms and counting: the dimensions of variation (such as contrast, generalisation, and fusion) expanded during the activity. The content was analysed based on variation theory (Marton 2015); however, the learning activities were analysed using Chi's (2009) framework. The third step in the analysis of the two activities assessed the ways in which the activities consisted of active, constructive, or interactive structures. An analysis was also made of the implicative characteristics of the overt and cognitive processes.

\section{Results}

The results are presented in accordance with the study's specific objectives. First, the results of the research questions are presented: RQ1 (What differences are evident in two preschool teachers' enactment of the same mathematical activity for children?) and RQ2 (How do these differences contribute to the variety of learning opportunities for the children?).

The analyses of the measured number words uttered by the teachers and children show a difference between what was said during the two activities (Table 3). The analysis indicates that the Boxes activity includes a greater variation of which forms of the number are discussed, and by that the opportunity to simultaneously discern nominal, ordinal, and cardinal forms of the number as well as equinumerosity. In Table 3, the design of the lesson also showed that a wider range of number representations were used in the activity with boxes, i.e., digits (written symbols), fingers (real-world situation), boxes (manipulated model), dots (pictured), and verbalisations (spoken symbols) based on Lesh's (1981) definitions. In the Cups activity, only two representations were offered: digits (symbols), and verbalisations (words). This shows a difference in the enactment of the activities, 

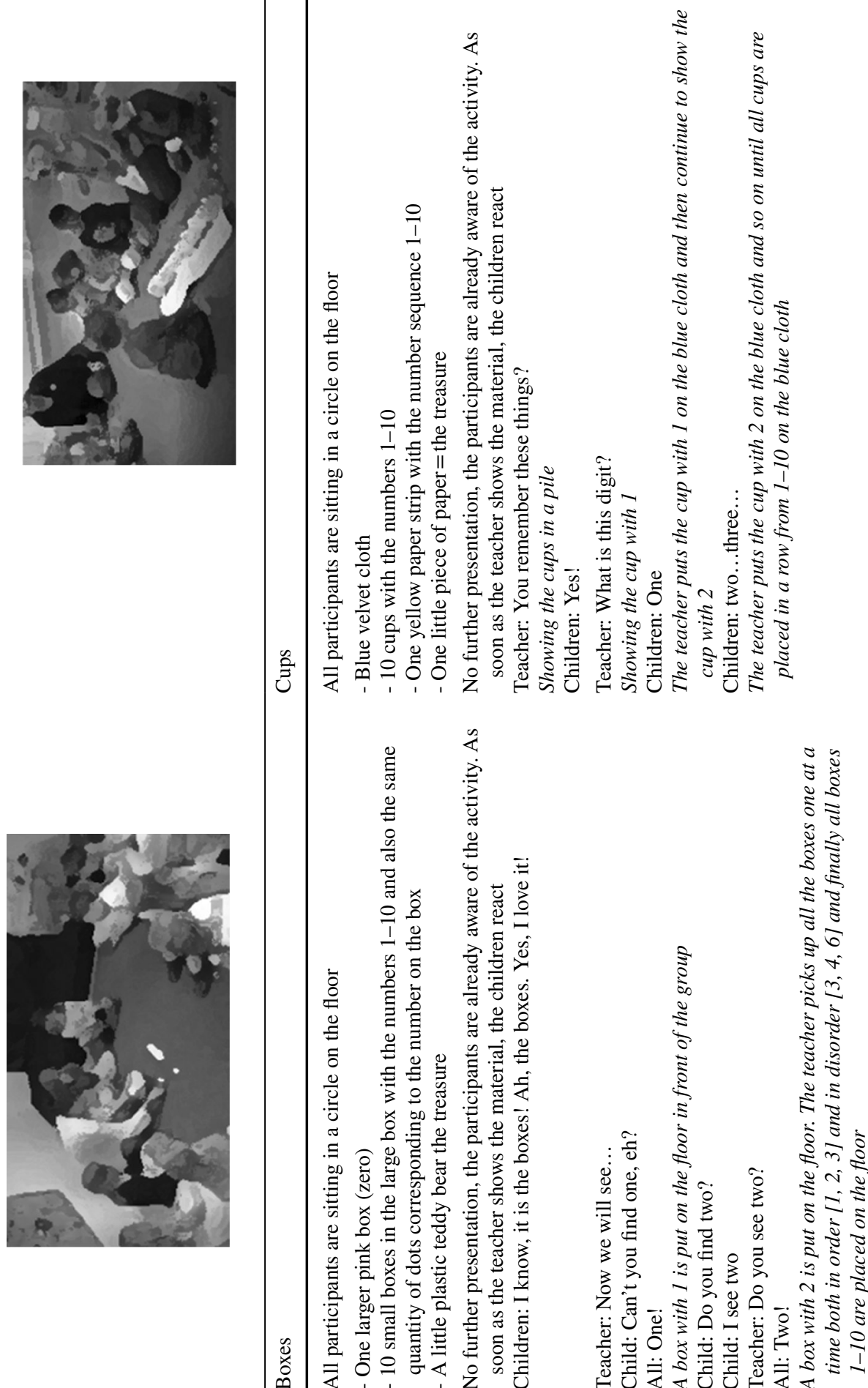

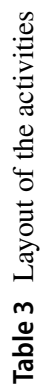

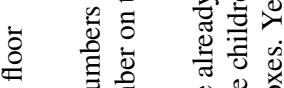

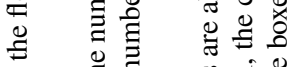

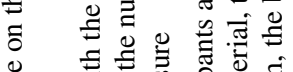

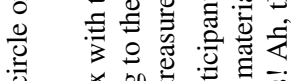

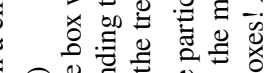

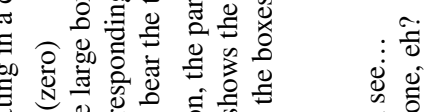

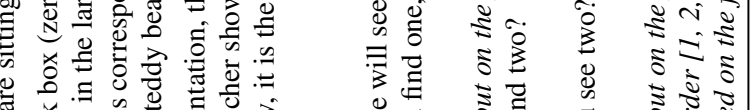

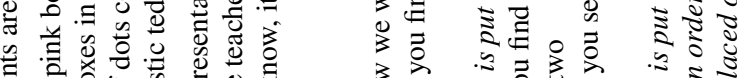

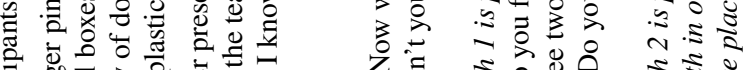

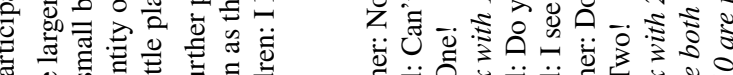

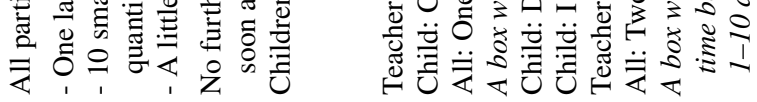

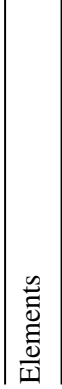

|
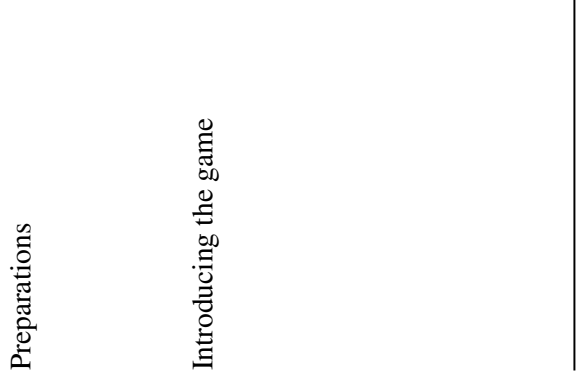


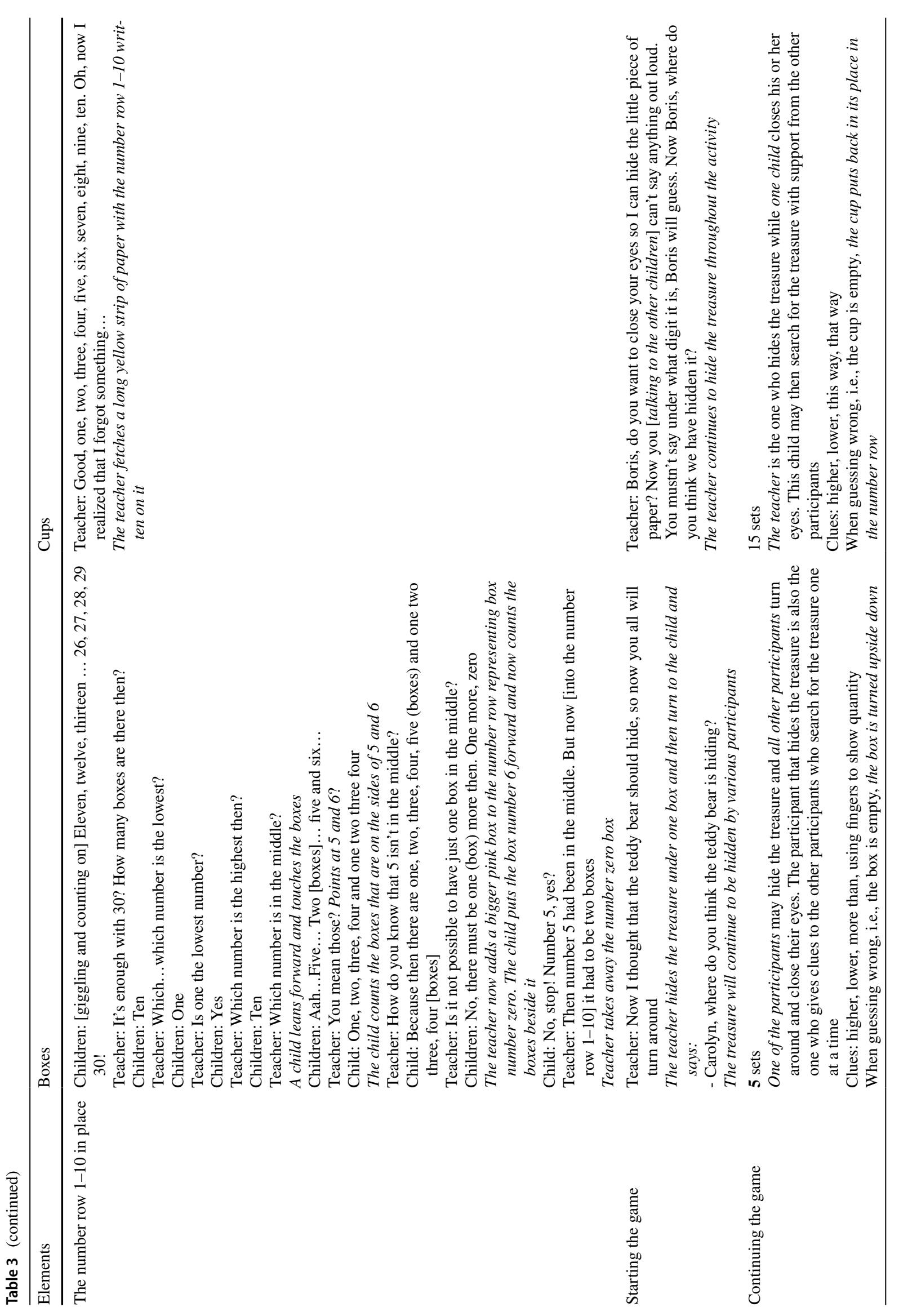


although they are inspired by the same game. The teachers also had slightly different approaches regarding the children's activities: the children in the Cups activity only let one child in the group close her or his eyes, while all children in the Boxes activity closed their eyes except for the one who hid the treasure. Another prominent finding was that the teachers used the Swedish word for digit (siffra) when talking about numbers instead of the Swedish word tal. This means that when the teachers talk about 10 , it becomes difficult to use the word 'digit' because the two digits are not separate but combined in a number (tal). In English, it would be equivalent to naming 10 as a digit.

\section{Differences Found in the Enactments of the Activity (RQ1)}

A prominent result of the analyses is the direction of the activity, where the Cups activity is more clearly teacherdirected play than the Boxes activity, which is more of a teacher-initialized play. The activities were divided into six levels after defining the setting and materials used, i.e., preparation, introducing the game, starting the game, the number row 1-10 in place, continuing the game, and wrapping up. The layout of all activities in each group is described in Table 4. Even if the duration of the Boxes activity was slightly shorter (12 min $21 \mathrm{~s}$ ) than the Cups activity (14 min $30 \mathrm{~s}$ ), the former provided more learning opportunities. First of all, all children were active in the Boxes activity because all of them guessed where the treasure was; by contrast, one child was guessing and watched by the others in the Cups activity. There was also a difference in the amount of repetitions, with five repetitions in the Boxes activity and 15 in the Cups activity.

Furthermore, based on Chi's (2009) framework, there were also differences in the enactments. The Cups activity did not include many active, constructive, or interactive aspects. However, there were parts of active processes. For example, in the beginning, the children were physically engaged in the placement of the cups, and they also performed some engaging activities because they needed to look, gaze, and fixate on the cups and their numbers. It is not easy to tell whether the children were involved in cognitive processes, but if they had not already developed knowledge of the relationship between the written digit and its verbal sound, they might have been involved in active cognitive processes. The Boxes activity was more focused on constructive and interactive processes. For example, the order of the boxes was negotiated between the teacher and the children, which opens up constructive processes where the children are free to express ideas that go beyond the presented information. The Boxes activity also provided examples of self-constructive activities, as the students were asked in a way to make them reason about their acts or outcomes. 
Whether the children were creating processes to develop new knowledge was not studied because the children's prior and post-knowledge were not assessed. However, there was a strong focus on interactive processes in the Boxes activity, where the teachers continuously discussed and reflected upon all children's expressions and guided them to reflect on and re-think the situation. When the number row was in place, the teacher challenged the children's thinking by giving them a task to find the 'middle' of the boxes by putting the numbers and dots on the boxes into the background and dividing the boxes into two groups to find the middle.

This example of providing opportunities to develop equinumerosity knowledge is also a good example of illustrating learning opportunities based on a variation theoretical analysis. The dimensions of variation are limited regarding the Cups activity but are rich in contrasting the numbers with each other and connecting the digits to their verbal representation. With the Boxes activity, patterns of variation were found for the contrasting number forms (nominal, ordinal, and cardinal) simultaneously. This makes the activity more complex and suits children who have developed the basic learning about numbers already and need some more challenges. The activity where the children were asked to find the 'middle' is an example of fusion, which requires the knowledge of several aspects of the object of learning. The children must discern the verbal and written form of digits to understand equinumerosity and also that three is always $\bullet \bullet$ items. Furthermore, the students must shift their focus and ignore the signs on the boxes to see them as new parts of another whole (i.e., two equal groups of boxes with different signs). This equality only refers to the exact number of boxes in both parts, showing that four boxes is the same as four other boxes regardless of their symbols (i.e., digits and dots).

\section{Differences Contributing to the Variety of Learning Opportunities (RQ2)}

The children's expressions were measured to identify the differences in the enactment of the learning activity. The results of this analysis (Table 4) show similarities in what is expressed by the children and the enactment of the activities (i.e. the children speak more in the Boxes activity), which had more interactive processes.

In the Boxes activity, the teachers expressed $43 \%$ of the number words, while the children expressed $57 \%$. In the Cups activity, the situation was reversed, with $63 \%$ and $37 \%$ of the number words expressed by the teachers and children, respectively. Differences were also observed in the distribution of nominal, ordinal, and cardinal number words. All three forms were represented in the Boxes activity, which had a more complex design, although the cardinal form was the least frequently spoken. In the Cups activity, there was a strong focus on the nominal and ordinal forms, and it was mainly the teacher who spoke. Regarding equinumerosity, this was only captured in the complex Boxes activity. Here, when wrapping up, the teachers and children worked with ordinal and cardinal number forms simultaneously, as shown in the excerpt below:

Teacher: Calle can you give me the box that has three dots [shows three fingers]?

Three, three dots, please.

Calle gives the teacher the box with three dots.

[...].

Teacher: Eight. Charlotte can you give me one that is lower than eight?

Charlotte gives the teacher the box with 5 .

Teacher: Five. Clara, someone give me one higher than five, a higher digit than five, please.

Clara gives the teacher the box with 7 .

Teacher: Cissi, higher than the digit seven?
Table 4 Distribution of number words among teacher and children

\begin{tabular}{|c|c|c|c|c|}
\hline \multirow[t]{2}{*}{ Distribution of expressions } & \multicolumn{2}{|l|}{ Boxes } & \multicolumn{2}{|l|}{ Cups } \\
\hline & Teachers & Children & Teachers & Children \\
\hline \multirow[t]{2}{*}{ Verbal number words } & $\mathrm{n}=122$ & & $\mathrm{n}=110$ & \\
\hline & $52(43 \%)$ & $70(57 \%)$ & $69(63 \%)$ & $41(37 \%)$ \\
\hline \multirow[t]{2}{*}{ Nominal (names) } & $\mathrm{n}=40^{*}$ & & $\mathrm{n}=94$ & \\
\hline & $16(40 \%)$ & $16(40 \%)$ & $53(56 \%)$ & $41(44 \%)$ \\
\hline \multirow[t]{2}{*}{ Ordinal (order) } & $\mathrm{n}=49$ & & $\mathrm{n}=14$ & \\
\hline & $27(55 \%)$ & $22(45 \%)$ & $0(0 \%)$ & $0(0 \%)$ \\
\hline \multirow[t]{2}{*}{ Cardinal (amount) } & $\mathrm{n}=7$ & & $\mathrm{n}=0$ & \\
\hline & $1(14 \%)$ & $6(86 \%)$ & - & - \\
\hline \multirow[t]{2}{*}{ Equinumerosity (ordinal + cardinal) } & $\mathrm{n}=26$ & & $\mathrm{n}=2$ & \\
\hline & $8(47.5 \%)$ & $18(52.5 \%)$ & $1(50 \%)$ & $1(50 \%)$ \\
\hline
\end{tabular}

*Eight (20\%) of the words were simultaneous because the teachers and children were counting together 
Cissi first touches the box with 1, then the box with 4 and also the box with $6 \ldots$

Teacher: ... more than seven.

[...].

Teacher: Cemal, lower than nine.

Cemal picks up the box with 8 .

Teacher: Can you give me number four, Cecil?

Cecil gives the teacher the last box, number 4 .

[...].

Teacher: Not this time, because how many boxes were there?

Children: 10.

The teacher shows all of her fingers.

Teacher: And how many children were there?

Children: 12.

Teacher: Yes, 10 boxes were there [teacher shows all of her fingers]. Was there a box for everyone, then?

Children: No!

In the Cups activity, there was no special learning opportunity when they wrapped up the activity.

Teacher: Good. I think you are very good with this. And now everybody has been tested. Time for a break. I'm going to take these away, and it's time for a bit of fruit.

The teacher collects the cups and put them together, also taking away the number rows and the blue cloth used as a carpet for marking where the activity took place.

\section{Discussion}

The aim of this study was to analyse how preschool teachers differently enacted the same mathematical activity for preschool children to learn to discern numbers, and in what way this affected the children's learning opportunities during the activity. The results underline the importance for preschool teachers to have sound didactical knowledge: they have to make the right choices for learning activities for preschool children. In this study, the activities were initially teacherdirected play, based on the same instruction of the treasure game. However, the direction of the activity did undergo a slight change during the study. Apart from observing this change in the direction, the present investigation makes a contribution about how different aspects of teaching content are made discernible and how this affects children's learning opportunities depending on their prior knowledge.

The ways in which the teachers interpreted and designed the activity resulted in two different versions of the playbased activity about the treasure. The activity was intended to develop children's cardinal understanding. Cardinality has been found to be important for children's mathematical learning (Resnick 1983; Cross et al. 2009); thus, studying how preschool teachers try to develop their students' knowledge is important. This study had two specific objectives. The first was to describe the number and nature of the numerical words used in the two activities, based on an assumption that to be able to develop knowledge, the children must be introduced to the learning content. The results show differences between the activities regarding what aspects of numbers were focused on in the activities. In the Boxes activity, the cardinal aspect was offered by the simultaneous presentation of numbers in nominal and cardinal forms, as digits and dots ( $3 \bullet \bullet \bullet)$ were visible on the top of the boxes. The ordinal form was also present, as the boxes were placed in order from 0 to 10 . This finding is in line with the results of Papadakis, Kalogiannakis and Zaranis (2017), who demonstrated that various kinds of stimuli enhanced children's ability to discover mathematical concepts. However, in the present study, some children might have found the use of the words 'higher' and 'lower' instead of 'more' or 'less' to be confusing; especially those sitting at the start or end of the number row, as the line could give the impression of a tower or house instead. In the Cups activity, the nominal form of the numbers was the study focus. Research has shown that of the five enumeration principles, the cardinal principle is the most challenging to learn (Gelman and Gallistel 1986), and very few of the number words referred to cardinality in both activities. By offering information in written form, the enactment of the activity and the teachers' different understandings of its assumptions about children's learning resulted in two diverse opportunities for the children's learning.

The second objective was to uncover in what way the differences between the Cups and Boxes activities affected the children's learning opportunities, depending on the combination of different designs and the students' prior knowledge. One important finding is how difficult it is to transfer knowledge of robust teaching methods by modelling best practices or powerful lesson designs. In this study, the same activity was inspired by the PBL activities that the teachers studied; however, the activity was experienced very differently within the perspective of the children's learning opportunities. The Boxes activity was more complex and required the children to have more prior knowledge, while the Cups activity focused on the relationship between the written symbols and spoken forms of numbers. The results from the second question show how these differences contributed to a variety of learning opportunities for the children (i.e., the activities were adjusted for different kinds of learning). However, it is unclear if this result was based on the knowledge of the students' learning or personal choices for enactment based on the teachers' opinions. We used variation theory to analyse the results (Marton 2015); thus, the dimensions of variation used were described. The Boxes 
activity used a greater variety of dimensions, e.g., the nominal, ordinal, and cardinal forms were used in both written/ symbolic and verbal representations. These differences are important and both activities are powerful, depending on the children's prior knowledge. However, the Boxes activity was more promising considering cardinality. Cardinality is considered the basis for counting, number operations, and solving complex mathematical tasks (Clements and Sarama 2014); therefore, this finding should be favourable for future mathematical learning. However, based on variation theory, if the children have not yet matched the verbal form of the number with the written form, the Cups activity is probably preferable for these children. Perhaps this aspect of the relational aspect between what knowledge the children have and how teachers can adjust the lesson design based on this knowledge is the most important factor when developing children's learning opportunities. Although this study cannot answer these questions, they would be an interesting focus for future studies.

This study not only focuses on the handling of the content but also the activities themselves; thus, two theoretical frameworks were used to define opportunities for children's PBL activities. Based on Chi's (2009) processes of activities, the analyses showed differences in the characteristics of the moments in the Boxes and Cups activities, where the interactive approach was more prominent in the Boxes activity. The Boxes activity was also found to be the most complex in its opportunities for patterns of variation, considering variation theory analysis (Marton 2015). Differences can also be found when analysing who and what the participants were speaking about and which participants spoke about what and when. In the more complex design of the Boxes activity, the children were the main speakers, and following the guidance of the teacher who opened up challenging dimensions of variation regarding aspects to focus on, the children had the opportunity to express and develop knowledge in new ways. This finding is in line with Bermejo et al. (2004), who used contradictions and cognitive conflicts to enhance the children's learning opportunities.

Another important variable can be found in whether the activity was child centred or teacher directed: the Boxes activity was much more child directed than the Cups one. This finding supports the results of Lerkkanen et al. (2016) about child-centred activities being more powerful for children's learning than teacher-directed ones. An argument against this is that a child-centred activity might not challenge children's knowledge, and a teacher-directed activity can be strongly based on the children's perspectives. Accordingly, variation theory contributes by defining the aspects offered to children during activities and how affordances meet the children's needs. The Boxes activity required more prior knowledge on the part of the children than did the Cups activity. This makes it difficult to determine whether child-centred or teacher-directed activities account for the differences found.

Equinumerosity (Sarnecka and Wright 2013) could be experienced in the Boxes activity: the teacher frequently showed the amount with her fingers when someone said a number; in written form on the boxes, the number was also represented by dots. The 'finding-the-middle' activity also showed another opportunity for equinumerosity development in the children's knowledge. By using the boxes in another way, the represented number equality was shown by groups of items with the same amount when searching for the 'middle'. This activity seems to be a good example of an interactive activity where the children have the simultaneous opportunity to understand equinumerosity and cardinality (Sarnecka and Wright 2013).

\section{Conclusions}

The study results show how the same preschool mathematics learning activity is interpreted and enacted differently by preschool teachers. First of all, the differences gave the children different opportunities to discern that numbers have different forms; in particular, the cardinal form was implicitly enacted in the Cups activity. In the Boxes activity, more aspects were discernible and the activities also had another characteristic: the interactive approach. The children's verbal expressions were more prominent in this activity. The children used number words with a cardinal meaning more often than the teacher did in the Boxes activity; however, this teacher continuously provided the opportunity to discern cardinality in written forms during the activity. In the Boxes activity, both teachers and children also used numbers with an understanding of equinumerosity more frequently. Thus, teachers who provide the opportunity for children to experience more complex and contradictory activities based on their prior knowledge enhance the children's learning opportunities.

\section{Limitations}

The children's learning was not measured in this study, which is a limitation because we cannot say anything about whether the offered learning situations actually did result in knowledge development.

Acknowledgements We thank Peter Fogarty, MA English 1st Class, from Edanz Group (https://en-author-services.edanzgroup.com/), for editing a draft of this manuscript. We are also grateful for the very valuable comments from the reviewers of the manuscript; they made a significant change to the quality of the paper compared with previous versions. 
Funding Open access funding provided by Malmö University.

\section{Compliance with Ethical Standards}

Conflict of Interest The authors declare that they have no conflict of interest.

Open Access This article is licensed under a Creative Commons Attribution 4.0 International License, which permits use, sharing, adaptation, distribution and reproduction in any medium or format, as long as you give appropriate credit to the original author(s) and the source, provide a link to the Creative Commons licence, and indicate if changes were made. The images or other third party material in this article are included in the article's Creative Commons licence, unless indicated otherwise in a credit line to the material. If material is not included in the article's Creative Commons licence and your intended use is not permitted by statutory regulation or exceeds the permitted use, you will need to obtain permission directly from the copyright holder. To view a copy of this licence, visit http://creativecommons.org/licenses/by/4.0/.

\section{References}

Baroody, A. J. (1987). Children's mathematical thinking. New York: Teachers College.

Bermejo, V., Morales, S., \& Deosuna, J. G. (2004). Supporting children's development of cardinality understanding. Learning and Instruction, 14(4), 381-398.

Björklund, C., \& Barendregt, W. (2016). Teachers' pedagogical mathematical awareness in Swedish early childhood education. Scandinavian Journal of Educational Research, 60(3), 359-377.

Breive, S., Carlsen, M., Erfjord, I., \& Hundeland, P. S. (2018). Designing playful inquiry-based mathematical learning activities for kindergarten. In C. Benz, A. Steinweg, H. Gasteiger, P. Schöner, H. Vollmuth, \& J. Zöllner (Eds.), Mathematics education in the early years. Cham, Switzerland: Springer.

Brownell, W. A. (1947). The place of meaning in the teaching of arithmetic. Elementary School Journal, 47, 256-265.

Carpenter, T., \& Moser, M. (1982). The development of addition and subtraction problem-solving skills. In T. Carpenter, J. Moser, \& T. Ronberg (Eds.), Addition and subtraction: A cognitive perspective. Hillsdale, NJ: Lawrence Erlbaum Associates.

Chi, M. T. H. (2009). Active-constructive-interactive: a conceptual framework for differentiating learning activities. Psychology in Education.

Clements, D. H. (1999). Subitizing. What is it? Why teach it? Teaching Children Mathematics, 5(7), 400-405.

Clements, D. H., \& Sarama, J. (2007). Effects of a preschool mathematics curriculum: summative research on the Building Blocks project. Journal for Research in Mathematics Education, 38, 136-163. https://doi.org/10.2307/30034954.

Clements, D. H., \& Sarama, J. (2014). Learning and teaching early math. The learning trajectories approach (2nd ed.). New York: Routledge.

Cross, C. T., Woods, T. A., \& Schweingruber, H. (2009). Mathematics learning in early childhood: paths toward excellence and equity. Washington, DC: National Academic Press.

Davydov, V. V. (1982). Psychological characteristics of the formation of mathematical operations in children. In T. P. Carpenter, J. M. Moser, \& T. A. Romberg (Eds.), Addition and subtraction: cognitive perspective (pp. 225-238). Hillsdale, NJ: Lawrence Erlbaum Associates.
Fuson, K. C., \& Hall, J. W. (1983). The acquisition of early number word meanings: A conceptual analysis and review. In H. P. Ginsburg (Ed.), The development of mathematical thinking (pp. 49-107). New York: Academic Press.

Fuson, K. C. (1988). Children's counting and concept of number. New York: Springer.

Fuson, C. K. (1991). Children's early counting: Saying the numberword sequence, counting objects, and understanding cardinality. In K. Durkin \& B. Shire (Eds.), Language and mathematical education (pp. 27-39). Milton Keynes, GB: Open University Press.

Fuson, K. (1992). Relationships between counting and cardinality from age 2 to age 8. In J. Bideaud, C. Meljac, \& J.-P. Fischer (Eds.), Pathways to number: Children's developing numerical abilities (pp. 127-150). Hillsdale, NJ: Lawrence Erlbaum Associates.

Gelman, R., \& Gallistel, C. (1986). The child's understanding of number. Cambridge, MA: Harvard University Press.

Gelman, R., \& Meck, B. (1992). Early principles aid initial but not later conceptions of number. In J. Bideaud, C. Meljac, \& J.-P. Fischer (Eds.), Pathways to number: Children's developing numerical abilities (pp. 171-189). Hillsdale, NJ: Lawrence Erlbaum Associates.

Holmqvist, M. (2011). Teachers' learning in a learning study. Instructional Science, 39(4), 497-511.

Holmqvist, M., Gustavsson, L., \& Wernberg, A. (2014). Variation theory: an organizing principle to guide design research in education. In A. E. Kelly, R. Lesh, \& J. Baek (Eds.), Handbook of design research methods in education (pp. 129-148). London: Routledge.

Howden, H. (1989). Teaching number sense. Arithmetic Teacher, 36, 6-11.

Kaufman, E. L., Lord, M. W., Reese, T. W., \& Volkman, J. (1949). The discrimination of visual number. American Journal of Psychology, 62, 498-525. https://doi.org/10.2307/1418556.

Kullberg, A., \& Björklund, C. (2019). Preschoolers' different ways of structuring part-part-whole relations with finger patterns when solving an arithmetic task. ZDM, 1-12.

Lerkkanen, M. K., Kiuru, N., Pakarinen, E., Poikkeus, A. M., RaskuPuttonen, H., Siekkinen, M., et al. (2016). Child-centered versus teacher-directed teaching practices: associations with the development of academic skills in the first grade at school. Early Childhood Research Quarterly, 36, 145-156.

Lesh, R. (1981). Applied mathematical problem solving. Educational Studies in Mathematics, 12, 235-264.

Marton, F. (2015). Necessary conditions of learning. New York: Routledge.

McIntosh, A., Reys, B. J., \& Reys, R. E. (1992). A proposed framework for examining basic number sense. For the Learning of Mathematics, $12,2-8$.

Olsson, I., \& Forsbäck, M. (1998). Tankeutmaningar. Nämnaren, 2, $16-19$.

Papadakis, S., Kalogiannakis, M., \& Zaranis, N. (2017). Improving mathematics teaching in kindergarten with realistic mathematical education. Early Childhood Education Journal, 45(3), 369-378.

Pyle, A., \& Bigelow, A. (2015). Play in kindergarten: an interview and observational study in three Canadian classrooms. Early Childhood Education Journal, 43(5), 385-393.

Qi, C. H., Kaiser, A. P., \& Milan, S. (2006). Children's behavior during teacher-directed and child-directed activities in Head Start. Journal of Early Intervention, 28(2), 97-110.

Resnick, L. B. (1983). A developmental theory of number understanding. In H. P. Ginsburg (Ed.), The development of mathematical thinking (pp. 109-151). New York: Academic Press.

Reys, B. J., \& Reys, R. E. (1995). Perspektiv på Number sense och taluppfattning. Nämnaren, 1, 28-33.

Sarnecka, B. W., \& Wright, C. E. (2013). The idea of an exact number: children's understanding of cardinality and equinumerosity. Cognitive Science, 37, 1493-1506. 
Swedish National Agency for Education. (2016). Curriculum for the preschool, Lpfö98. Stockholm: Fritzes.

Swedish National Agency for Education. (2018). Curriculum for the preschool, Lpfö18. Stockholm: Fritzes.

Swedish National Agency for Education. (2019). Curriculum for the compulsory school, preschool class and school-age education, Lgr11. Stockholm: Fritzes.

Taylor, M. E., \& Boyer, W. (2020). Play-based learning: evidencebased research to improve children's learning experiences in the kindergarten classroom. Early Childhood Education Journal, 48(2), 127-133.

Wickstrom, H., Pyle, A., \& DeLuca, C. (2019). Does theory translate into practice? An observational study of current mathematics pedagogies in play-based kindergarten. Early Childhood Education Journal, 47(3), 287-295.

Wynn, K. (1989). Children's understanding of counting. Paper presented at the Biennial Meeting of the Society for Research in Child Development. Kansas City, April 1989.

Wynn, K. (1992). Children's acquisition of the number words and the counting system. Cognitive Psychology, 24, 220-251.

Publisher's Note Springer Nature remains neutral with regard to jurisdictional claims in published maps and institutional affiliations. 